\title{
Highly sensitive lens culinaris agglutinin-reactive $\alpha$-fetoprotein is useful for early detection of hepatocellular carcinoma in patients with chronic liver disease
}

\author{
KOHEI ODA ${ }^{1}$, AKIO IDO $^{1}$, TSUTOMU TAMAI ${ }^{1}$, MASAKAZE MATSUSHITA ${ }^{2}$, KOTARO KUMAGAI ${ }^{1}$, \\ SEI-ICHI MAWATARI ${ }^{1}$, AKIKO SAISHOJI ${ }^{1}$, TAKESHI KURE ${ }^{1}$, KAORI OHNO ${ }^{1}$, ERIKO TOYOKURA ${ }^{1}$, \\ DAI IMANAKA ${ }^{1}$, AKIHIRO MORIUCHI $^{1}$, HIROFUMI UTO ${ }^{1}$, MAKOTO OKETANI ${ }^{1}$, \\ TERUTO HASHIGUCHI ${ }^{2}$ and HIROHITO TSUBOUCHI ${ }^{1}$ \\ ${ }^{1}$ Digestive Disease and Life-style Related Disease, Kagoshima University Graduate School of Medical \\ and Dental Sciences; ${ }^{2}$ Division of Clinical Laboratory, Kagoshima University Hospital, Japan
}

Received June 24, 2011; Accepted July 18, 2011

DOI: $10.3892 / o r .2011 .1425$

\begin{abstract}
The fucosylated fraction of $\alpha$-fetoprotein (AFPL3) is a specific marker for hepatocellular carcinoma (HCC). However, conventional AFP-L3\% (c-AFP-L3\%) has not always been reliable in cases with low serum $\alpha$-fetoprotein (AFP) levels. In this study, we evaluated the clinical utility of a newly developed assay, highly sensitive AFP-L3\% (hs-AFP-L3\%). Subjects included 74 patients with benign liver disease (BLD), including chronic hepatitis and cirrhosis, and 94 with HCC. Serum hs-AFP-L3\% was significantly higher than c-AFP-L3\% in patients with early-stage HCC (solitary or $<20 \mathrm{~mm}$ in diameter). Additionally, hs-AFP-L3\% was significantly increased in patients with well-differentiated HCC. In patients with serum AFP $<20 \mathrm{ng} / \mathrm{ml}$, the sensitivities of c-AFP-L3\% and hs-AFP-L3\% were 12.5 and $44.6 \%$, respectively, at a cut-off value of $5 \%$. In $59 \mathrm{BLD}$ patients with serum AFP $<20 \mathrm{ng} / \mathrm{ml}$, the HCC-positive rate in patients with hs-AFP-L3\% $\geq 5 \%$ was significantly higher compared to those with hs-AFP-L3\% $<5 \%$ during the follow-up period (median, 35 months; range, 5-48 months). Importantly, none of the BLD patients with both serum AFP $<20 \mathrm{ng} / \mathrm{ml}$ and hs-AFP-L3\% $<5 \%$ developed HCC. These results indicated that hs-AFP-L3\% is useful for early detection of HCC in BLD patients, even for those with serum AFP $<20 \mathrm{ng} / \mathrm{ml}$. Furthermore, since hs-AFP-L3\% increases before HCC is detectable by various advanced imaging modalities, this assay may help identify BLD patients with a higher risk of HCC.
\end{abstract}

Correspondence to: Dr Akio Ido, Digestive Disease and Life-style Related Disease, Kagoshima University Graduate School of Medical and Dental Sciences, 8-35-1 Sakuragaoka, Kagoshima 880-8520, Japan

E-mail: ido-akio@m2.kufm.kagoshima-u.ac.jp

Key words: $\alpha$-fetoprotein, $\alpha$-fetoprotein fucosylated fraction L3, hepatocellular carcinoma, hepatocarcinogenesis

\section{Introduction}

Hepatocellular carcinoma (HCC) is the sixth most common cancer in the world, and the third most common cause of cancer-related death (1). Although it is more common in Asia and Africa, its incidence in the United States has increased over the past two decades, largely due to the spread of hepatitis $\mathrm{C}(\mathrm{HCV})$ infection, which is an underlying risk factor (2). Early detection of HCC increases the potential for curative treatment and improves prognosis. Several methods developed for the diagnosis of HCC, including evaluation of serum markers, ultrasonography (US), computed tomography (CT) and magnetic resonance imaging (MRI), have been tested clinically. $\alpha$-fetoprotein (AFP) and des- $\gamma$ carboxy prothrombin (DCP), serum proteins that are elevated in $\mathrm{HCC}$, are the most widely used markers. Although routine screening offers the best chance for early tumor detection, the reported sensitivities and specificities of elevated serum AFP and DCP levels vary significantly (3-8). Furthermore, serum AFP levels increase in only $30-40 \%$ of patients with HCC, especially early in the disease process (5). Additionally, an increase in serum AFP is also seen in patients with non-cancerous conditions, including cirrhosis or exacerbation of chronic hepatitis (9). AFP-L3, the lectin lens culinaris agglutinin-bound fraction, is one of the three glycoforms of AFP, and is the major glycoform elevated in the serum of HCC patients. The reported sensitivities of AFP-L3 as a method of detecting HCC range from 75-97\% with specificities of $90-92 \%(10,11)$. In cases of HCC, however, high percentage of AFP-L3 is closely associated with poor differentiation and biologically malignant characteristics, including portal vein invasion, of neoplastic cells $(11,12)$. Therefore, it is not clear how useful this test is for the early detection of HCC. Additionally, measurement of AFP-L3 has not always been reliable for serum samples with low total AFP concentration, as determined by conventional lectin affinity system (LiBASys) (13).

Recently, a novel automated immunoassay for AFP-L3 has been developed. The new method uses on-chip electrokinetic reaction and separation by affinity electrophoresis (micro-total 
analysis system; $\mu$-TAS) (14). In patients with an AFP level of $\geq 20 \mu \mathrm{g} / \mathrm{ml}, \mu$-TAS AFP-L3\% correlated well with LiBASys AFP-L3\% (15). Furthermore, this system has enabled the accurate measurement of AFP-L3\% at very low AFP concentrations. Therefore, in this retrospective study, we investigated the clinical utility of the new highly sensitive $\mu$-TAS AFP-L3\% assay for diagnosis of HCC in a population of patients with HCC or benign liver diseases (BLD), including chronic hepatitis or cirrhosis.

\section{Patients and methods}

Patients. Between December 2006 and September 2010, frozen serum samples were obtained from 94 patients with HCC, as well as from 74 patients with BLD, who had chronic hepatitis or liver cirrhosis, but not HCC (Table I). All patients met the eligibility criteria (availability of stored serum samples and written informed consent). Among the BLD patients, 20 were positive for hepatitis B surface antigen (HBsAg), 43 were positive for anti-hepatitis $\mathrm{C}$ virus (HCV) antibody, and 11 were negative for either HBsAg or anti-HCV antibody. The BLD patients were followed after serum sampling for $32.8 \pm 12.3$ months (median, 35 ; range, 5-48); liver imaging was performed by US at $6-$ to 12-month intervals in most patients with chronic hepatitis, and CT, MRI, or US was performed at 3- to 6-month intervals in patients with liver cirrhosis.

HCC patients were diagnosed using imaging modalities such as US, MRI and CT during hepatic arteriography. Vascular invasion was evaluated by imaging modalities. In some cases that showed atypical features upon imaging, ultrasoundguided biopsies were performed. Based on imaging findings, tumor stage was ranked using the tumor-node-metastasis (TMN) staging system of the Liver Cancer Study Group of Japan $(16,17)$ : T1 (fulfilling the following three conditions: solitary, $2 \mathrm{~cm}$, no vessel invasion), T2 (fulfilling two of the three conditions), $\mathrm{T} 3$ (fulfilling one of the three conditions), T4 (fulfilling none of the three conditions or showing presence of distant metastasis); N0 (no lymph node metastasis), N1 (metastasis to lymph nodes); M0 (no distant metastasis), M1 (distant metastasis); stage 1 (T1NOM0), stage II (T2N0M0), stage III (T3NOM0), and stage IV (T4NOM0 or any TN1M0, or any TN0-1M1).

Measurement of serum AFP and AFP-L3\%. For the HCC group, AFP and AFP-L3\% were measured in the same sample obtained at the time of HCC diagnosis, before any treatment. For the BLD without HCC group, measurements were made at the time of diagnosis of chronic liver disease. Highly sensitive AFP-L3\% (hs-AFP-L3\%) were measured by a microchip capillary electrophoresis and liquid-phase binding assay on a $\mu$-TASWako i30 auto analyzer (Wako Pure Chemical Industries, Ltd., Osaka, Japan) (15). Conventional AFP-L3\% (c-AFP-L3\%) was examined using a column chromatography and liquidphase binding assay on a LiBASys auto analyzer (Wako Pure Chemical Industries, Ltd.) (13). The analytical sensitivity of the $\mu$-TASWako i30 auto analyzer is $0.3 \mu \mathrm{g} / \mathrm{ml}$ AFP; the AFP-L3\% can be measured when AFP-L3 is over $0.3 \mu \mathrm{g} / \mathrm{ml}$. Although the analytical sensitivity of the LiBASys is $0.8 \mu \mathrm{g} / \mathrm{ml}$ AFP, AFP-L3\% cannot be measured at AFP $<10 \mathrm{ng} / \mathrm{ml}$. Therefore, the correlation between $\mu$-TAS-L3\% and LiBA-L3\% was poor at $\mathrm{AFP}<20 \mathrm{ng} / \mathrm{ml}$.
Statistical analysis. We used the Mann-Whitney U test, Z test and Chi-square test for evaluation of the statistical significance of each finding. SPSS version 17.0J (SPSS Inc., Chicago, IL, USA) was used to perform statistical analysis; $\mathrm{p}<0.05$ was considered to indicate statistical significance.

\section{Results}

Clinical feature of patients. The demographics, etiology of liver disease, hepatic functional reserve ranked by Child-Pugh classification, tumor stage, tumor size and tumor number of the study patients are summarized in Table I. The HCC group included 94 patients: 35 patients with stage I, 35 with stage II, 14 with stage III, and 10 with stage IV; thus, $75 \%$ of HCC cases were stage I or II. The incidence of cirrhosis in HCC patients (55.3\%) was significantly higher than in BLD (25.7\%), whereas the hepatic reserve expressed by Child-Pugh classification of HCC patients was significantly preserved compared with BLD patients.

Serum AFP levels in patients with HCC were significantly higher than those with BLD (Table I and Fig. 1A). hs-AFPL3\% was measurable in 47.3 and $78.7 \%$ of patients with BLD and HCC, respectively, whereas C-AFP-L3\% was detected in 31.1 and $63.8 \%$ of patients. Thus, hs-AFP-L3\% was significantly higher than c-AFP-L3\% in both BLD and HCC patients (Table I and Fig. 1B). Since a cut-off value of 5\% has been reported to be useful for diagnosis of HCC using hs-AFP-L3\% (18), the cut-off value for AFP-L3\% was set at 5\% in the present study. The sensitivity and specificity of hs-AFP-L3\% were 57.0 and $63.5 \%$, respectively, whereas those of c-AFP-L3\% were 40.4 and $81.1 \%$.

hs-AFP-L3\% significantly increases in HCC patients at early stage. Next, we analyzed serum AFP levels, c-AFP-L3\% and hs-AFP-L3\%, and compared early and advanced stages of HCC (Fig. 2). When compared with HCC patients with stage I or II cancer, serum AFP levels were significantly increased in patients with stage III and IV disease (Fig. 2A). Both c-AFP-L3\% and hs-AFP-L3\% in HCC patients with advanced stages were also significantly higher than in patients with early stages (Fig. 2B). Although $86 \%$ of HCC patients with stage I $(n=35)$ exhibited serum AFP $<20 \mathrm{ng} / \mathrm{ml}$, c-AFP-L3\% and hs-AFP-L3\% were measurable in 46 and $69 \%$ of these patients, respectively; hs-AFP-L3\% was significantly higher than c-AFP-L3\%. Consequently, in HCC patients at stage I, the sensitivity of c-AFP-L3\% or hs-AFP-L3\% at a cut-off level of $5 \%$ were 17.1 or $48.6 \%$, respectively.

Next, we evaluated the relationship between AFP-L3\% and tumor number or size (Fig. 3). hs-AFP-L3\% was significantly higher than c-AFP-L3\%, even in patients with single or small HCC ( $<20 \mathrm{~mm}$ in diameter) (Fig. 3). Conversely, when compared to HCC patients with solitary or small HCC, both c-AFP-L3\% and hs-AFP-L3\% were increased in cases with multiple or $\geq 20 \mathrm{~mm} \mathrm{HCC}$, and there was no statistical difference between c-AFP-L3\% and hs-AFP-L3\%. These results indicate that hs-AFP-L3\% is a useful biomarker for detecting early-stage HCC.

An increase in hs-AFP-L3\% is observed in both BLD and $H C C$ patients with AFP $<20 \mathrm{ng} / \mathrm{ml}$. We analyzed c-AFP-L3\% 
Table I. Clinical features of patients with BLD and HCC.

\begin{tabular}{|c|c|c|c|}
\hline & BLD $(n=74)$ & $\mathrm{HCC}(\mathrm{n}=94)$ & $\mathrm{p}$-value \\
\hline Age & $56.23 \pm 13.88$ & $65.76 \pm 12.98^{\mathrm{a}}$ & $<0.001$ \\
\hline Gender (male/female) & $30 / 44$ & $56 / 38^{a}$ & 0.015 \\
\hline $\mathrm{CH} / \mathrm{LC}$ & $55 / 19$ & $42 / 52^{\mathrm{a}}$ & $<0.001$ \\
\hline $\mathrm{HBV} / \mathrm{HCV} / \mathrm{NBNC}$ & $20 / 43 / 11$ & $5 / 61 / 28^{\mathrm{a}}$ & $<0.001$ \\
\hline \multicolumn{4}{|l|}{ Child-Pugh class } \\
\hline (A/B/C/unknown) & $39 / 5 / 4 / 26$ & $75 / 19 / 0 / 0^{\mathrm{a}}$ & $<0.001$ \\
\hline TNM stage (I/II/III/IV) & & $35 / 35 / 14 / 10$ & \\
\hline Tumor size (mean $\pm \mathrm{SD})$ & & $22.35 \pm 16.42$ & \\
\hline$<20 \mathrm{~mm} / \geq 20 \mathrm{~mm}$ & & $58 / 36$ & \\
\hline Tumor number (single/multiple) & & $50 / 44$ & \\
\hline $\operatorname{AFP}(\mathrm{ng} / \mathrm{ml})$ & $46.17 \pm 163.6$ & $2871.5 \pm 9882.7^{\mathrm{a}}$ & $<0.001$ \\
\hline c-AFP-L3\% & $2.96 \pm 6.45$ & $18.19 \pm 26.95^{\mathrm{a}}$ & $<0.001$ \\
\hline hs-AFP-L3\% & $3.84 \pm 5.59$ & $21.12 \pm 29.01^{\mathrm{a}}$ & $<0.001$ \\
\hline Platelet count $\left(\times 10^{4} / \mu 1\right)$ & $14.98 \pm 6.82$ & $11.39 \pm 4.73^{\mathrm{a}}$ & 0.001 \\
\hline $\operatorname{AST}(\mathrm{IU} / \mathrm{l})$ & $70.55 \pm 95.87$ & $55.78 \pm 22.92$ & 0.099 \\
\hline $\operatorname{ALT}(\mathrm{IU} / \mathrm{l})$ & $85.38 \pm 144.71$ & $48.28 \pm 24.13$ & 0.783 \\
\hline
\end{tabular}

$\mathrm{BLD}$, benign liver disease; $\mathrm{HCC}$, hepatocellular carcinoma; $\mathrm{CH}$, chronic hepatitis; LC, liver cirrhosis; HBV, hepatitis B virus; HCV, hepatitis $\mathrm{C}$ virus; hs-AFP-L3\%, hypersensitive-AFP-L3\%; c-AFP-L3\%, conventional-AFP-L3\%.

A

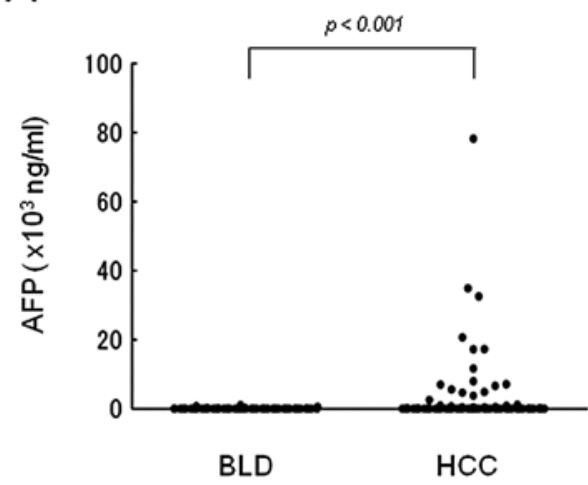

B

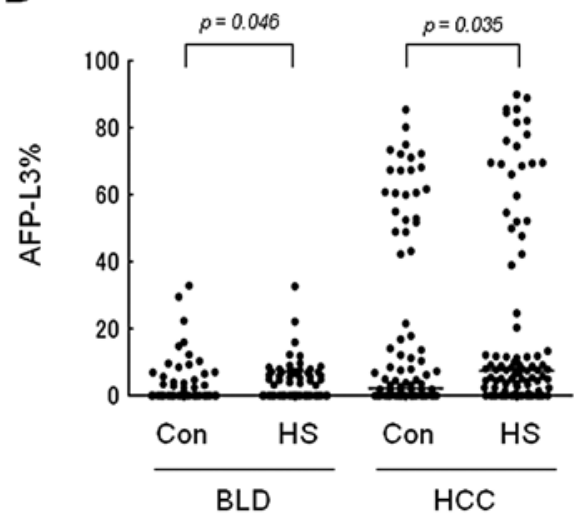

Figure 1. Serum levels of AFP, c-AFP-L3\% and hs-AFP-L3\% in patients with BLD or HCC. (A) Serum AFP concentrations in HCC patients $(n=94)$ were significantly higher than those in BLD ( $n=74)$. (B) hs-AFP-L3\% (HS) significantly increased in comparison with c-AFP-L3\% (Con) in both BLD and HCC patients.

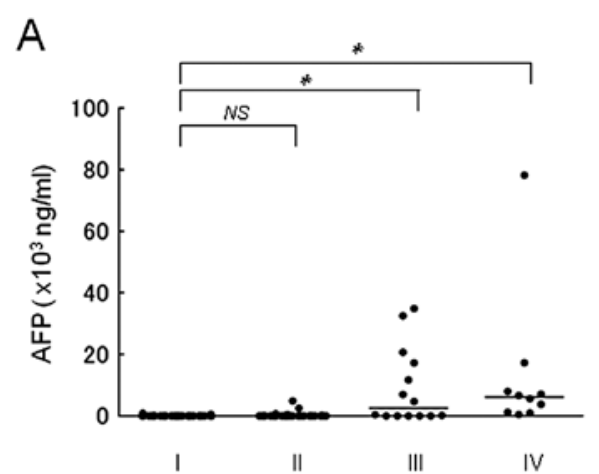

B

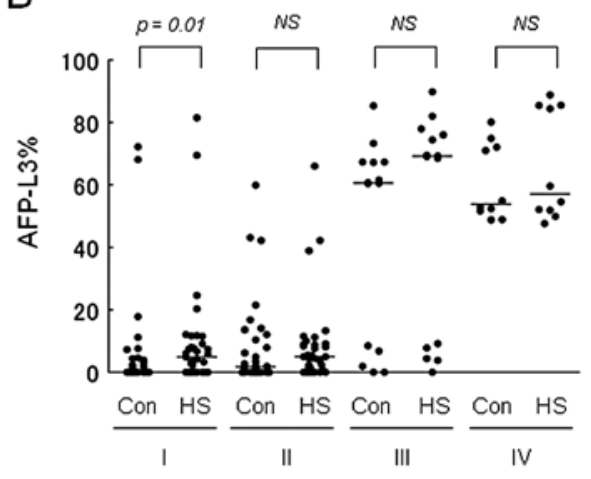

Figure 2. Serum levels of AFP, c-AFP-L3\% and hs-AFP-L3\% in patients with early or advanced HCC. (A) Serum AFP levels in HCC patients at stage III $(n=14)$ or IV $(n=10)$ were significantly higher than those at stage I $(n=35)$ or II $(\mathrm{n}=35) .{ }^{*} \mathrm{p}<0.05$. (B) hs-AFP-L3\% (HS) was significantly higher than c-AFPL3\% (Con) in patients with $\mathrm{HCC}$ at stage I, whereas there was no significant difference between c- and hs-AFP-L3\% in HCC patients at stages II, III and IV. 
Table II. Clinical features of BLD and HCC patients with AFP $<20 \mathrm{ng} / \mathrm{ml}$.

\begin{tabular}{|c|c|c|c|}
\hline & $\operatorname{BLD}(\mathrm{n}=59)$ & $\mathrm{HCC}(\mathrm{n}=56)$ & p-value \\
\hline Age & $56.78 \pm 13.51$ & $68.88 \pm 12.05^{\mathrm{a}}$ & $<0.001$ \\
\hline Gender (male/female) & $23 / 36$ & $26 / 30$ & 0.422 \\
\hline $\mathrm{CH} / \mathrm{LC}$ & $45 / 14$ & $25 / 31^{\mathrm{a}}$ & 0.001 \\
\hline $\mathrm{HBV} / \mathrm{HCV} / \mathrm{NBNC}$ & $14 / 35 / 10$ & $5 / 32 / 19^{a}$ & 0.008 \\
\hline \multicolumn{4}{|l|}{ Child-Pugh class } \\
\hline (A/B/C/unknown) & $31 / 4 / 1 / 23$ & $50 / 6 / 0 / 0^{\mathrm{a}}$ & $<0.001$ \\
\hline TNM stage (I/II/III/IV) & & $30 / 21 / 5 / 0$ & \\
\hline Tumor size (mean \pm SD) & & $16.16 \pm 11.59$ & \\
\hline$<20 \mathrm{~mm} / \geq 20 \mathrm{~mm}$ & & $47 / 9$ & \\
\hline Tumor number (single/multiple) & & $35 / 21$ & \\
\hline $\operatorname{AFP}(n g / m l)$ & $4.68 \pm 3.6$ & $8.92 \pm 5.23^{\mathrm{a}}$ & $<0.001$ \\
\hline c-AFP-L3\% & $0.83 \pm 3.92$ & $1.86 \pm 3.16^{\mathrm{a}}$ & 0.002 \\
\hline hs-AFP-L3\% & $2.7 \pm 5.15$ & $4.86 \pm 5.19^{\mathrm{a}}$ & 0.003 \\
\hline Platelet count $\left(\mathrm{x} 10^{4} / \mu \mathrm{l}\right)$ & $15.93 \pm 6.67$ & $11.93 \pm 4.49^{\mathrm{a}}$ & 0.001 \\
\hline $\operatorname{AST}(\mathrm{IU} / \mathrm{l})$ & $43.91 \pm 25.72$ & $54.32 \pm 21.61^{\mathrm{a}}$ & 0.003 \\
\hline ALT (IU/1) & $49.21 \pm 51.7$ & $48.66 \pm 24.41$ & 0.184 \\
\hline
\end{tabular}

BLD, benign liver disease; HCC, hepatocellular carcinoma; $\mathrm{CH}$, chronic hepatitis; LC, liver cirrhosis; HBV, hepatitis B virus; HCV, hepatitis $\mathrm{C}$ virus; hs-AFP-L3\%, hypersensitive-AFP-L3\%; c-AFP-L3\%, conventional-AFP-L3\%.

A

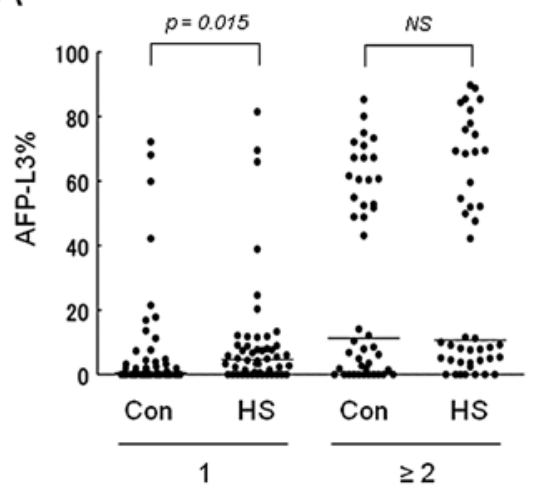

B

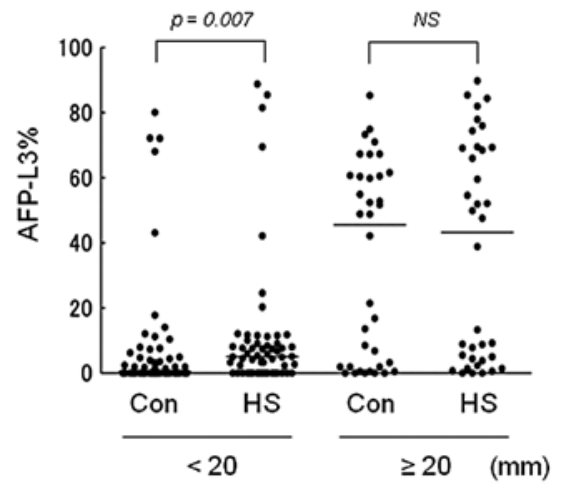

Figure 3. hs-AFP-L3\% significantly increased in patients with solitary or small HCC, but not multiple or HCC $\geq 20 \mathrm{~mm}$ in diameter. (A) hs-AFP-L3\% (HS) was significantly higher than c-AFP-L3\% (Con) in patients with solitary HCC $(\mathrm{n}=50)$, but not in patients with multiple HCC $(\mathrm{n}=44)$. (B) hs-AFP-L3\% significantly increased in comparison with c-AFP-L3\% in patients with small HCC $(<20 \mathrm{~mm}$ in diameter) $(\mathrm{n}=58)$, but not in patients with large $\mathrm{HCC}(\geq 20 \mathrm{~mm})$ $(n=36)$.

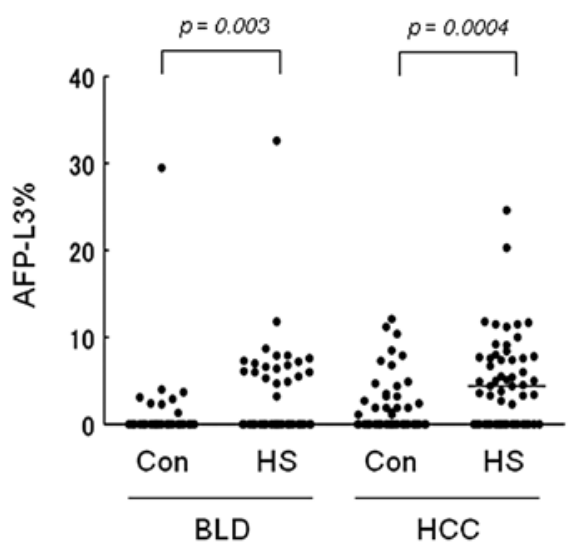

Figure 4. Higher levels of hs-AFP-L3\% were observed in both BLD and HCC patients with serum AFP $<20 \mathrm{ng} / \mathrm{ml}$. c-AFP-L3\% (Con) and hs-AFP-L3\% (HS) in BLD and HCC patients with AFP $<20 \mathrm{ng} / \mathrm{ml}$ ( $\mathrm{n}=59$ and 56 , respectively) were analyzed. c-AFP-L3\% was detectable in 13.6 and $39.3 \%$ of BLD and HCC patients, respectively, whereas hs-AFP-L3\% was measurable in 33.9 and $64.3 \%$ of BLD and HCC patients, respectively; hs-AFP-L3\% was significantly higher than c-AFP-L3\%.

and hs-AFP-L3\% in BLD and HCC patients with AFP $<20 \mathrm{ng} /$ $\mathrm{ml}$ (Table II). Forty-seven of $56(83.4 \%)$ HCC patients exhibited small HCCs (<20 mm in diameter); 35 patients $(62.5 \%)$ exhibited solitary tumors. c-AFP-L3\% was detectable in 13.6 and $39.3 \%$ of BLD and HCC patients, respectively. Conversely, hs-AFP-L3\% was measurable in 33.9 and $64.3 \%$ of BLD and HCC patients, respectively, and the levels of hs-AFP-L3\% were significantly higher than those of c-AFP-L3\% [BLD: mean \pm SD (range) $0.83 \pm 3.92(1.3-29.5)$ vs. $2.70 \pm 5.15 \%, \mathrm{p}=0.003$, and HCC: $1.86 \pm 3.16$ (1.1-12.1) vs. $4.86 \pm 5.19 \%$ (2.3-24.6), $\mathrm{p}=0.004]$ (Fig. 4). The sensitivity and specificity of hs-AFP-L3\% 
Table III. Characterization of seven BLD patients, who developed HCC.

\begin{tabular}{|c|c|c|c|c|c|c|c|}
\hline Case no. & 1 & 2 & 3 & 4 & 5 & 6 & 7 \\
\hline Age & 58 & 70 & 63 & 70 & 53 & 60 & 59 \\
\hline Gender & M & $\mathrm{F}$ & $\mathrm{F}$ & $\mathrm{F}$ & M & M & $\mathrm{F}$ \\
\hline $\mathrm{CH} / \mathrm{LC}$ & LC & $\mathrm{CH}$ & $\mathrm{LC}$ & $\mathrm{LC}$ & LC & $\mathrm{LC}$ & $\mathrm{CH}$ \\
\hline $\mathrm{HCV} / \mathrm{NBNC}$ & $\mathrm{HCV}$ & $\mathrm{HCV}$ & $\mathrm{HCV}$ & NBNC & $\mathrm{HCV}$ & $\mathrm{HCV}$ & $\mathrm{HCV}$ \\
\hline $\operatorname{AFP}(\mathrm{ng} / \mathrm{ml})$ & 5.3 & 8.3 & 10.7 & 10.9 & 27.8 & 28.5 & 32.0 \\
\hline c-AFP-L3\% & ND & ND & 29.5 & 4.9 & 15.9 & 12.2 & 3.4 \\
\hline hs-AFP-L3\% & 6.0 & 7.0 & 32.6 & 8.4 & 12.2 & 9.6 & 3.7 \\
\hline ALT (IU/l) & 31 & 48 & 23 & 39 & 41 & 65 & 116 \\
\hline Months until HCC detection & 13 & 31 & 5 & 13 & 18 & 8 & 31 \\
\hline
\end{tabular}

F, female; M, male; ND, not detectable.

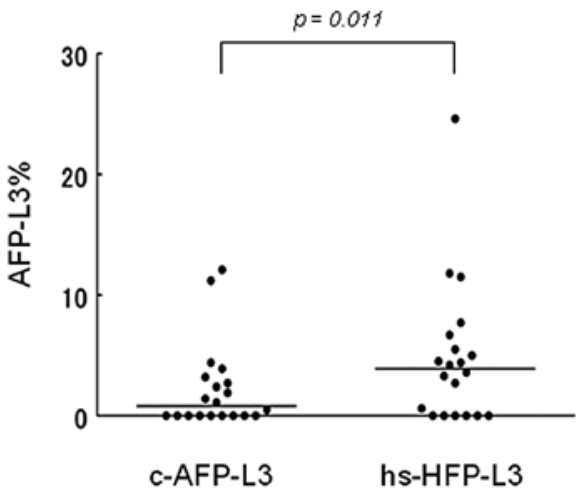

Figure 5. Patients with well-differentiated HCC showed an increase in hs-AFPL3\%. hs-AFP-L3\% (HS) was significantly higher than c-AFP-L3\% in patients with well-differentiated HCC; this was confirmed by histological examination.

at a cut-off level of $5 \%$ were 44.6 and $71.2 \%$, whereas those of c-AFP-L3\% were 12.5 and $98.3 \%$, respectively. These results suggest that hs-AFP-L3\% is useful for early detection of HCC, even when serum AFP is $<20 \mathrm{ng} / \mathrm{ml}$.

Serum hs-AFP-L3\% increases in patients with well-differentiated HCC. Most HCC, initially present as well-differentiated HCC, develops in patients with chronic liver disease. Therefore, we evaluated c-AFP-L3\% and hs-AFP-L3\% in 20 patients with well-differentiated HCC, which was confirmed by histological examination. Fifteen patients $(75.0 \%)$ exhibited small HCCs ( $<20 \mathrm{~mm})$, and $9(45.0 \%)$ suffered from liver cirrhosis. Serum AFP was $14.2 \pm 12.4 \mathrm{ng} / \mathrm{ml}(1.4-54.1)$, and 18 patients $(90 \%)$ exhibited serum AFP levels $<20 \mathrm{ng} / \mathrm{ml}$. hs-AFP-L3\% was measurable in 14 patients $(70 \%)$, while 11 patients $(55 \%)$ exhibited detectable levels of c-AFP-L3\% (Fig. 5). Consequently, hs-AFP-L3\% was significantly higher than c-AFP-L3\% [4.81 $\pm 5.91(0.6-24.6)$ vs. $2.24 \pm 3.53 \%(0.5-12.1), p=0.011]$. These results support the possible utility of hs-AFP-L3\% for detection of early-stage HCC.

hs-AFP-L3\% increases prior to detection of HCC in patients with BLD. Seven of 74 patients with BLD developed HCC

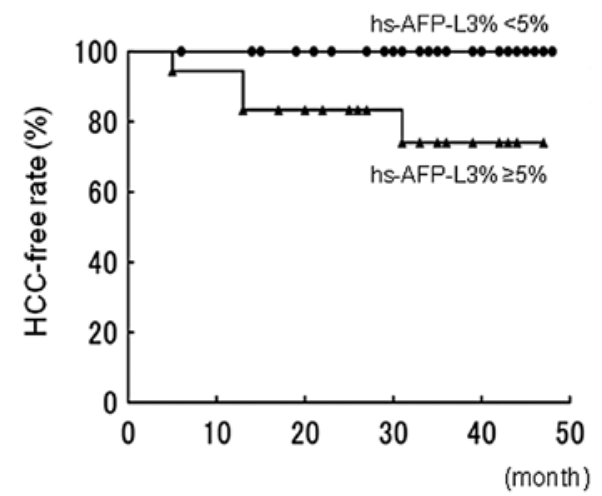

Figure 6. No patients with both serum AFP $<20 \mathrm{ng} / \mathrm{ml}$ and hs-AFP-L3\% $<5 \%$ developed HCC. Patients with BLD ( $n=74)$ were periodically followed by US, $\mathrm{CT}$, or MRI during the follow-up period (median, 35 months; range, 5-48 months). In cases of BLD with AFP $<20 \mathrm{ng} / \mathrm{ml}(\mathrm{n}=59), \mathrm{HCC}$ was newly detected in 4 patients with hs-AFP-L3\% $\geq 5 \%$. The HCC-free rate in patients with hsAFP-L3\% $\geq 5 \%$ ( $\mathbf{\Delta}$ ) was significantly higher than in patients with hs-AFP-L3\% $<5 \%(\bullet)(\log$-rank test and Wilcoxon test; $\mathrm{p}=0.0012$ and $\mathrm{p}=0.0017$, respectively) Importantly, no patients with hs-AFP-L3\% <5\% developed HCC.

during the follow-up period (median, 35 months; range, 5-48) (Table III). Five patients suffered from liver cirrhosis, and 6 exhibited hepatitis $\mathrm{C}$ virus infection. Two of the patients with chronic hepatitis required a longer period (31 months) for appearance of HCC than did the 5 patients with cirrhosis (5-18 months). Five patients exhibited measurable c-AFP-L3\%, and an increase in c-AFP-L3\% ( $\geq 5 \%$ ) was observed in 3 patients. In contrast, hs-AFP-L3\% was measurable in all 7 patients prior to detection of HCC, and 6 patients (85.7\%) exhibited hs-AFP$\mathrm{L} 3 \% \geq 5 \%$. In $59 \mathrm{BLD}$ patients with serum AFP $<20 \mathrm{ng} / \mathrm{ml}, 4$ patients developed HCC (Table III). An increase in c-AFPL3\% ( $\geq 5 \%$ ) was observed only in 1 patient, who developed HCC during the follow-up period, whereas the other three patients exhibited undetectable levels or $<5 \%$ of c-AFP-L3\%. Conversely, all 4 patients with serum AFP $<20 \mathrm{ng} / \mathrm{ml}$ exhibited an increase in hs-AFP-L3\% ( $\geq 5 \%$ ) prior to detection of HCC.

Next, we analyzed the HCC-free rate in BLD patients with serum AFP $<20 \mathrm{ng} / \mathrm{ml}$ during the follow-up period (Fig. 6). The HCC-free rate in patients with hs-AFP-L3\% $\geq 5 \%$ was 
significantly higher than those with hs-AFP-L3\% $<5 \%$. Of importance, $\mathrm{HCC}$ was not detected in BLD patients with both serum AFP $<20 \mathrm{ng} / \mathrm{ml}$ and hs-AFP-L3\% $<5 \%$, whereas 3 out of 58 patients with both serum AFP $<20 \mathrm{ng} / \mathrm{ml}$ and $<5 \%$ of c-AFPL3\% developed HCC. These results suggest that an increased hs-AFP-L3\% allows prediction of HCC development; measurement of hs-AFP-L3\% is useful for selecting BLD patients with higher risk of HCC.

\section{Discussion}

Most HCC occurs in patients with chronic liver diseases, especially cirrhosis. Therefore, periodical measurement of tumor markers for HCC, such as AFP and DCP, is recommended in patients who are at high risk for HCC. However, recent advances in diagnostic imaging techniques, including US, $\mathrm{CT}$ and MRI, facilitate the detection of small and early-stage HCC (19-21), resulting in an increase in the number of HCC patients diagnosed without an observed increase in serum AFP. Indeed, the 18th survey and follow-up study of primary liver cancer in Japan has reported that most patients with HCC exhibited low levels of serum AFP, $<15 \mathrm{ng} / \mathrm{ml}$. Additionally, although AFP-L3\% status is known to be a specific marker for HCC, measurement of c-AFP-L3\% has not always been reliable in patients with AFP $<20 \mathrm{ng} / \mathrm{ml}$.

In this study, we investigated the clinical utility of hs-AFPL3\%, which was measured by a newly developed and highly sensitive method, $\mu$-TAS, in patients with BLD and HCC. Here, we showed that although most HCC patients with stage I cancer did not exhibit an increase in serum AFP levels ( $\geq 20 \mathrm{ng} /$ $\mathrm{ml}$ ), hs-AFP-L3\% was measurable in $\sim 70 \%$ of the patients, and was significantly increased in comparison with c-AFP-L3\% (Fig. 2). Since hs-AFP-L3\% is reliable even when serum AFP is $<20 \mathrm{ng} / \mathrm{ml}$, it is possible to set the cut-off value for hs-AFPL3\% at $5-7 \%(18,22,23)$. We show here that at a cut-off level of $5 \%$, the sensitivity and specificity of hs-AFP-L3\% were 44.6 and $71.2 \%$, respectively, in HCC patients with serum AFP $<20 \mathrm{ng} / \mathrm{ml}$ (Fig. 4). Recent investigations have shown that diagnostic sensitivity of hs-AFP-L3\% at a cut-off level of 5 or $7 \%$ was 41.5 or $41.1 \%$, respectively, in HCC patients with serum AFP $<20 \mathrm{ng} / \mathrm{ml}(18,22)$. Therefore, our findings in this study support the specificity of hs-AFP-L3\% in patients with serum AFP $<20 \mathrm{ng} / \mathrm{ml}$, as previously reported.

The sensitivity of c-AFP-L3\% is relatively low (22.2-38.6\%) in early-stage HCCs $<20 \mathrm{~mm}$ in diameter $(24,25)$. In this study, although the sensitivity of c-AFP-L3\% was $<20 \%$ in patients with HCC at stage I, hs-AFP-L3\% was significantly higher than c-AFP-L3\% in patients with solitary or small $(<20 \mathrm{~mm}) \mathrm{HCC}$ or with stage I HCC (Figs. 2 and 3); consequently, $50 \%$ of HCC patients at stage I exhibited hs-AFP-L3\% $\geq 5 \%$. Additionally, in patients with well-differentiated HCC, hs-AFP-L3\% was also significantly higher than c-AFP-L3\%. Conversely, patients with stage III or IV HCC (multiple or larger $(\geq 20 \mathrm{~mm})$ tumors) exhibited an increase in both hs- and c-AFP-L3\%, with no statistical difference. HCC initially develops as well-differentiated HCC, and then progresses to moderately- to poorly-differentiated HCC via a process of dedifferentiation. Thus, an increase in hs-AFPL3\% in patients with well-differentiated HCC and early-stage HCC supports the conclusion that measurement of hs-AFP-L3\% is useful for early detection of HCC.
HCC often develops in patients with chronic infection of hepatitis $\mathrm{B}$ or $\mathrm{C}$ virus; especially in patients with chronic $\mathrm{HCV}$ infection, the annual incidence of $\mathrm{HCC}$ increases as a function of the stage of liver fibrosis, from $0.5 \%$ at stages $\mathrm{F} 0$ to $\mathrm{F} 1$ to $7.9 \%$ at stage F4 (cirrhosis) (26). Recently, Tateyama et al demonstrated that elevated AFP levels are a risk factor for the development of $\mathrm{HCC}$ in patients with $\mathrm{HCV}$ infection; the 10 -year cumulative incidence rates of HCC in the patients with AFP levels of $<6,6-20$ and $\geq 20 \mathrm{ng} / \mathrm{ml}$ at entry were $6.0,24.6$ and $47.3 \%$, respectively, and that AFP levels may be used as a non-invasive and predictive marker in place of stage of fibrosis (27). In this study, all 7 BLD patients who developed HCC during the follow-up period exhibited measurable hs-AFP-L3\% prior to detection of HCC, and 6 patients exhibited hs-AFP-L3\% $\geq 5 \%$. Of particular note, even when serum AFP levels increased to up to $20 \mathrm{ng} / \mathrm{ml}, \mathrm{HCC}$ was not detected in patients with hs-AFP-L3\% <5\% (Fig. 6).

Although prolonged observation will be required in order to clarify whether hs-AFP-L3\% is useful for prediction of $\mathrm{HCC}$, the findings presented here indicated that hs-AFP-L3\% is useful for early detection of HCC in BLD patients even with serum AFP $<20 \mathrm{ng} / \mathrm{ml}$, and also that an increase in hs-AFPL3\% prior to detection of HCC by various advanced imaging modalities may contribute to more precisely identifying BLD patients with a higher risk of HCC.

\section{Acknowledgements}

The authors thank Yuko Nakamura-Morinaga for technical assistance. This study was supported by funds from the Ministry of Education, Culture, Sports, Science and Technology of Japan, and from the Ministry of Health, Labour and Welfare.

\section{References}

1. Parkin DM, Bray F, Ferlay J and Pisani P: Global cancer statics. 2002. CA Cancer J Clin 55: 74-108, 2005.

2. El-Serag HB and Masson AC: Rising incidence of hepatocellular carcinoma in the United States. N Eng J Med 340: 745-750, 1999.

3. Oka H, Tamori A, Kuroki T, Kobayashi K and Yamamoto S: Prospective study of alpha-fetoprotein in cirrhotic patients monitored for development of hepatocellular carcinoma. Hepatology 19: 61-66, 1994.

4. Ishii M, Gama H, Chida N, Ueno Y, Shinzawa H, Takagi T, Toyota T, Takahashi T and Kasukawa R: Simultaneous measurements of serum alpha-fetoprotein and protein induced by vitamin $\mathrm{K}$ absence for detecting hepatocellular carcinoma. South Tohoku District Study Group. Am J Gastroenterol 85: 1036-1040, 2000.

5. Okuda H, Nakanishi T, Takatsu K, Saito A, Hayashi N, Takasaki K, Takenami K, Yamamoto M and Nakano M: Serum levels des-gamma-carboxy prothrombin measured using the revised enzyme immunoassay kit with increased sensitivity in relation to clinicopathologic features of solitary hepatocellulat carcinoma. Cancer 88: 544-549, 2000.

6. Grazi GL, Mazziotti A,LegnaniC, Jovine E,Miniero R, Gallucci A, Palareti G and Gozzetti G: The role of tumor markers in the diagnosis of hepatocellular carcinoma, with special reference to ethe des-gamma-carboxy prothrombin. Liver Transpl Surg 1: 249-255, 1995.

7. Wang CS, Lin CL, Lee HC, Chen KY, Chiang MF, Chen HS, Lin TJ and Liao LY: Usefulness of serum des-gamma-carboxy prothrombin in detection of hepatocellular carcinoma. World $\mathbf{J}$ Gastroenterol 11: 6115-6119, 2005.

8. Marrero JA, Su GL, Wei W, Emick D, Conjeevaram HS, Fontana RJ and Lok AS: Des-gammma carboxy prothrombin can differentiate hepatocellular carcinoma from nonmalignant chronic liver disease in American patients. Hepatology 37: 1114-1121, 2003.

9. Taketa K: Alpha-fetoprotein: reevaluation in hepatology. Hepatology 12: 1420-1432, 1999. 
10. Taketa K, Okada S, Win N, Hlaing NK and Wind KM: Evaluation of tumor markers for the detection of hepatocellular carcinoma in Yangon General Hospital, Myanmar. Acta Med Okayama 56: 317-320, 2002

11. Khien VV, Mao HV, Chinh TT, Ha PT, Bang MH, Lac BV, Hop TV, Tuan NA, Don LV, Taketa K and Satomura S: Clinical evaluation of lentil lectin-reactive alpha-fetoprotein-L3 in histology-proven hepatocellular carcinoma. Int J Biol Markers 16: 105-111, 2001.

12. Oka H, Saito A, Ito K, Kumada T, Satomura S, Kasugai H, Osaki Y, Seki T, Kudo M and Tanaka M: Collaborative HepatoOncology Study Group of Japan. Multicenter prospective analysis of newly diagnosed hepatocellular carcinoma with respect or the percentage of Lens culinaris agglutinin-reactive alpha-fetoprotein. J Gastroenterol Hepatol 16: 1378-1383, 2001.

13. Nakamura K, Imajo N, Yamagata Y, Katoh H, Fujio K, Tanaka T, Satomura S and Matsuura S: Liquid-phase binding assay of alpha-fetoprotein using a sulfated antibody for bound/free separation. Anal Chem 70: 954-957, 1998.

14. Kawabata T, Wada HG, Watanabe M and Satomura S: Electrokinetic analyte transport assay for alpha-fetoprotein immunoassay integrates mixing, reaction and separation on-chip. Electropheresis 29: 1399-1406, 2008.

15. Kagebayashi C, Yamaguchi I, Akinaga A, Kitano H, Yokoyama K, Satomura M, Kurosawa T, Watanabe M, Kawabata T, Chang W, Li C, Bousse L, Wada HG and Satomura S: Automated immunoassay system for AFP-L3\% using on-chip electrokinetic reaction and separation by affinity electrophoresis. Anal Biochem 388: 306-311, 2009.

16. Liver Cancer Study Group of Japan: General Rules for the Clinical and Pathological Study of Primary Liver Cancer. English edition. Kanehara, Tokyo, 2003.

17. Kudo M, Chung H and Osaki Y: Prognostic staging system for hepatocellular carcinoma (CLIP score): its value and limitations, and a proposal for a new staging system, the Japan Integrated Staging Score (JIS score). J Gastroenterol 38: 207-215, 2003.

18. Toyoda H, Kumada T, Tada T, Kaneoka Y, Maeda A, Kanke F and Satomura S: Clinical utility of highly sensitive lens culinaris agglutinin-reactive alpha-fetoprotein in hepatocellular carcinoma patients with alpha fetoprotein $<20 \mathrm{ng} / \mathrm{ml}$. Cancer Sci 102: 1025-1031, 2011.

19. Ikeda K, Saitoh S, Koida K, Tsubota A, Arase Y, Chayama K and Kumada H: Diagnosis and follow-up of small hepatocellular carcinoma with selective intraarterial digital subtraction angiography. Hepatology 17: 1003-1007, 1993.
20. Takayasu K, Moriyama N, Muramatsu Y, Makuuchi M, Hasegawa H, Okazaki N and Hirohashi S: The diagnosis of small hepatocellular carcinomas: efficacy of various imaging procedures in 100 patients. Am J Roentgenol 155: 49-54, 1990.

21. Takayasu K, Furukawa H, Wakao F, Muramatsu Y, Abe H, Terauchi T, Winter TC 3rd, Sakamoto $M$ and Hirohashi S: CT diagnosis of early hepatocellular carcinoma: sensitivity, findings, and CT-pathologic correlation. Am J Roentgenol 164: 885-890, 1995.

22. Tamura Y, Igarashi M, Kawai H, Suda T, Satomura S and Aoyagi Y: Clinical advantage of highly sensitive on-chip immunoassay for fucosylated fraction of alpha-fetoprotein in patients with hepatocellular carcinoma. Dig Dis Sci 55: 3576-3583, 2010.

23. Hanaoka T, Sato S, Tobita H, Miyake T, Ishihara S, Akagi S, Amano Y and Kinoshita Y: Clinical significance of high sensitive fucosylated fraction of alpha-fetoprotein in patients with chronic liver disease. J Gastroenterol Hepatol 26: 739-744, 2011.

24. Taketa K, Endo Y, Sekiya C, Tanikawa K, Koji T, Taga H, Satomura S, Matsuura S, Kawai T and Hirai H: A collaborative study for the evaluation of lectin-reactive alpha-fetoprotein in early detection of hepatocellular carcinoma. Cancer Res 53: 5419-5423, 1993.

25. Kumada T, Nakano S, Takeda I, Kiriyama S, Sone Y, Hayashi K, Katoh H, Endoh T, Sassa T and Satomura S: Clinical utility of lens culinaris agglutinin-reactive alpha-fetoprotein in small hepatocellular carcinoma: special reference to imaging diagnosis. J Hepatol 30: 125-130, 1999.

26. Yoshida H, Shiratori Y, Moriyama M, Arakawa Y, Ide T, Sata M, Inoue O, Yano M, Tanaka M, Fujiyama S, Nishiguchi S, Kuroki T, Imazeki F, Yokosuka O, Kinoyama S, Yamada $\mathrm{G}$ and Omata M: Interferon therapy reduces the risk of hepatocellular carcinoma: national surveillance program of cirrhotic and non cirrhotic patients with chronic hepatitis C in Japan. IHIT Study Group. Inhibition of Hepatocarcinogenesis by Interferon Therapy. Ann Intern Med 131: 174-181, 1999.

27. Tateyama M, Yatsuhashi H, Taura N, Motoyoshi Y, Nagaoka S, Yanagi K, Abiru S, Yano K, Komori A, Migita K, Nakamura M, Nagahama H, Sasaki Y, Miyakawa Y and Ishibashi H: Alpha-fetoprotein above normal levels as a risk factor for the development of hepatocellular carcinoma in patients infected with hepatitis C virus. J Gastroenterol 46: 92-100, 2011. 